\title{
Short communication: Validation of in vitro fertility genes in a Holstein bull population
}

\author{
H. Khatib, ${ }^{* 1}$ R. L. Monson, † W. Huang, ${ }^{*}$ R. Khatib, ${ }^{*}$ V. Schutzkus, ${ }^{*}$ H. Khateeb, ${ }^{*}$ and J. J. Parrish† \\ *Department of Dairy Science, and \\ †Department of Animal Sciences, University of Wisconsin-Madison, Madison 53706
}

\section{ABSTRACT}

Previously, we constructed an in vitro fertilization system for the identification of genes affecting fertility traits in dairy cattle. The efficiency of this system has been demonstrated by the identification of several genes affecting fertilization rate and early embryonic survival. However, to employ these genetic markers in markerand gene-assisted selection programs, there is a need to validate in vitro results in phenotypic data sets collected in vivo. Thus, the objective of this study was to validate, in a population of Holstein bulls, the fertility trait genes we previously identified in an in vitro system. Estimated relative conception rate (ERCR) data from 222 Holstein bulls were obtained from 5 different artificial insemination companies in the United States. Bulls were genotyped for the genes FGF2, POU1F1, PRL, PRLR, GH, GHR, STAT5A, OPN, and UTMP, and the data were analyzed for association with ERCR using a mixed effects sire model. A stepwise model selection procedure revealed evidence of association with ERCR for FGF2 and STAT5A polymorphisms. The in vivo validation suggests that these genes can be used in gene-assisted selection programs for reproductive performance in dairy cattle. The genotypes found to be associated with low bull fertility in this study have been reported to be associated with high milk composition in previous studies. These findings provide molecular evidence for the antagonistic relationship between milk production and fertility observed for many years in different breeds of dairy cattle.

Key words: bull fertility, candidate pathway, single nucleotide polymorphism

The intensive genetic selection for high milk production in dairy cows has been coupled with disruptions in hormonal balance and reduction of estrus intensity, which in turn has led to subfertility in high-producing cows (Royal et al., 2000; Dobson et al., 2008). Conse-

Received October 7, 2009.

Accepted January 25, 2010

${ }^{1}$ Corresponding author: hkhatib@wisc.edu quently, several countries are now including fertility indices in their selection programs (Miglior et al., 2005). Identification of genetic markers and understanding the molecular mechanisms involved in subfertility would help to restore reproductive performance of dairy cows through marker-assisted selection schemes (Beerda et al., 2008). Although heritability of fertility traits has been reported to be low in some studies (e.g., VanRaden et al., 2004), other studies have argued for strong genetic effects on fertility (Weigel, 2006; Veerkamp and Beerda, 2007). Shook (2006) estimated that genetics accounts for about one-third of the decline in pregnancy rate of dairy cows.

To identify genes involved in fertility traits in cattle, we have constructed an in vitro fertilization (IVF) system that enables us to identify genes affecting 2 measures of pregnancy: fertilization rate and early embryonic survival. Using this system, we have identified significant associations of several genes from the IFN- $\tau$ and the POU1F1 (pituitary-specific positive transcription factor 1) pathways with fertility traits (Khatib et al., 2008a,b, 2009a). The in vitro system has the advantage of unified environmental effects on the oocytes and the developing embryos. On the other hand, as with any other assisted reproductive technology (ART), gene effects observed in vitro are not necessarily replicated in vivo. As such, the objective of this study was to validate results obtained in previous in vitro studies in an in vivo data set of fertility measures collected on bulls used by the dairy industry in the United States.

Estimated relative conception rate (ERCR) data from 222 young and mature Holstein bulls were obtained from 5 AI companies in the United States from April through June 2001. Estimated relative conception rate is the difference in conception rate (nonreturn rate at $70 \mathrm{~d}$ ) of a sire compared with other AI sires used in the same herd (Clay and McDaniel, 2001). The nonreturn rate was estimated at $70 \mathrm{~d}$ for first insemination of lactating cows (www.aipl.arsusda.gov). The ERCR values for these 222 bulls ranged from -4.99 to +5.23 , and the number of breedings per bull ranged from 50 to 22,046. Semen samples were obtained from all bulls maintained by 4 of 5 AI stud companies in the United States, and 
Table 1. Genes, primer sequences, and PCR product sizes

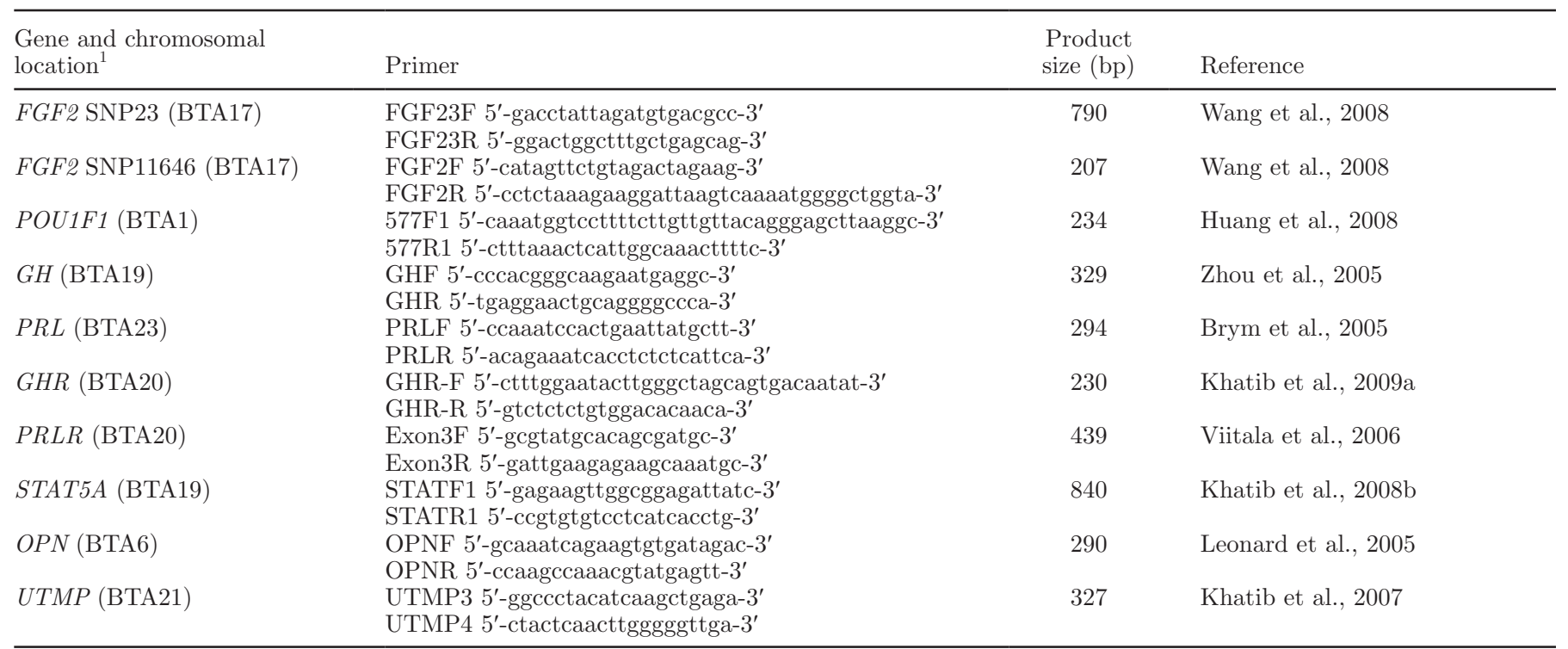

${ }^{1} F G F 2=$ fibroblast growth factor $2 ; P O U 1 F 1=$ pituitary-specific positive transcription factor $1 ; G H=$ growth hormone; $P R L=$ prolactin; $G H R$ $=$ growth hormone receptor; $P R L R=$ prolactin receptor; $S T A T 5 A=$ signal transducer and activator of transcription $5 \mathrm{~A} ; O P N=$ osteopontin; $U T M P=$ uterine milk protein.

DNA was extracted from semen using standard phenolchloroform protocols. The DNA concentrations were measured using a spectrophotometer (Ultraspec 2100, Amersham Biosciences, Piscataway, NJ). Genes, primers, and PCR product sizes are described in Table 1. Genotyping of SNP was performed as described in the references in Table 1.

To test associations between ERCR and SNP genotypes, a model selection strategy was adopted. The selection procedure started with a full model:

$$
\begin{aligned}
\text { ERCR }_{i j k l m}= & \mu+b_{1} \text { age }_{i}+\sum_{j=1}^{10} \sum_{k=1}^{3} b_{2 j k} \mathrm{SNP}_{j k} \\
& + \text { Stud }_{l}+\text { Sire }_{m}+\varepsilon_{i j k l m} .
\end{aligned}
$$

For the $i$ th animal, this mixed effects sire model contained a grand mean $\mu$, an age fixed effect $b_{1}$, fixed effects for the $k$ th genotype of the $j$ th SNP $b_{2 j k}$, random effects for $S t u d_{l}$ from which the animal originated and Sire $_{m}$ of the animal, and a residual term. Age was treated as a continuous covariate and SNP were coded by 3 genotype classes and treated as a categorical variable. The vectors of random effects Stud, Sire, and $\varepsilon$ were assumed to be distributed:

$$
\left(\begin{array}{c}
\text { Stud } \\
\text { Sire } \\
\varepsilon
\end{array}\right) \sim N\left[0, \quad\left(\begin{array}{ccc}
I \sigma_{s}^{2} & 0 & 0 \\
0 & A \sigma_{a}^{2} & 0 \\
0 & 0 & W^{-1} \sigma_{\varepsilon}^{2}
\end{array}\right)\right]
$$

in which $\mathbf{A}$ was the matrix of additive relationships between sires and $\mathbf{W}$ was a diagonal matrix with its elements representing reliabilities of ERCR responses. A was calculated based on a 5-generation pedigree of bulls downloaded from USDA AIPL using the INBREED procedure in SAS software (version 9.1.3, 2009; SAS Institute Inc., Cary, NC). The 222 bulls in the data set were offspring of 78 sires, which were sired by 38 bulls, then 24, and finally 15 bulls. Reliabilities of ERCR were calculated as

$$
100 \times\left[1-\left(1-\sqrt{\frac{n}{n+200}}\right) \times 2.3\right],
$$

where $n$ was the number of matings (http://aipl.arsusda.gov/reference/fertility/ercr.htm). Twenty-six bulls with negative reliabilities were excluded from the analysis. The model was fitted using the MIXED procedure in the SAS software. The SNP were selected in a stepwise manner using a 0.10 significance level. This significance level was chosen to increase statistical power because of the relatively small sample size, and the final model contained only SNP that reached this significance level. Based on the final model, contrasts between 3 genotypes were obtained for each genotype of every SNP. Additive effects for SNP were equivalent to the contrasts between the 2 homozygotes. Dominance effect for each SNP was assessed by testing the ERCR difference between the heterozygote and the average of the 2 homozygotes. To account for multiple hypothesis 
testing and control false discovery rate, the procedure by Benjamini and Hochberg (1995) was adopted, and the $q$-value for each contrast or test was obtained. For a statistical test, the $q$-value can be interpreted as the false discovery rate at which all hypotheses with smaller $q$-values are rejected.

Table 2 shows the Hardy-Weinberg equilibrium tests for the $10 \mathrm{SNP}$ investigated in this study [FGF2 (fibroblast growth factor 2; 2 SNP), POU1F1 (pituitaryspecific positive transcription factor 1), $G H$ (growth hormone), $P R L$ (prolactin); GHR (growth hormone receptor), PRLR (prolactin receptor), STAT5A (signal transducer and activator of transcription $5 \mathrm{~A}$ ), OPN (osteopontin), and UTMP (uterine milk protein)]. Only GH showed significant deviation from Hardy-Weinberg equilibrium. Given that 3 pairs of SNP are located on the same chromosomes (FGF2 SNP23 and FGF2 SNP11646 on BTA17, GH and STAT5A on BTA19, and GHR and PRLR on BTA20), pair-wise linkage disequilibrium tests that measure nonrandom associations of alleles among all SNP were calculated using $\mathrm{r}^{2}$ values. Only the 2 SNP of FGF2 were in moderate linkage disequilibrium $\left(\mathrm{r}^{2}=0.38\right)$. The SNP of PRLR and GHR $\left(\mathrm{r}^{2}=0.003\right)$ and those of STAT5A and $G H\left(\mathrm{r}^{2}=0.08\right)$ did not show remarkable linkage disequilibrium. A stepwise model selection procedure was used to develop a model containing only SNP that showed evidence of association. A significance level of 0.10 was chosen in the model selection procedure to leverage power with a relatively small sample size. Three SNP, STAT5A (type III F-test $P=0.029, q=0.082)$, FGF2.SNP11646 $(P$ $=0.044, q=0.082)$, and POU1F1 $(P=0.064, q=$ 0.096) were selected in the final model. These results are an important validation for our previous studies that reported the association of STAT5A and FGF2 with IVF fertility traits (Khatib et al., 2008a,b, 2009a). The estimated differences between the 3 genotypes and dominance effect for each SNP are given in Table 3. Interestingly, STAT5A $(P=0.008, q=0.082)$ and FGF2 SNP11646 $(P=0.026, q=0.082)$ showed significant dominance effects. For STAT5A, the estimated difference between GC and GG genotypes was 0.814 points and that between GC and CC genotypes was 0.442 points, suggesting some extent of overdominance (Table 3). For FGF2 SNP11646, the estimated difference between AA and GG genotypes was 0.793 points, suggesting dominance of the AA genotype (Table 3 ). For POU1F1, the dominance effect was not significant (Table 3).

Recently, we reported the identification of genes affecting fertility traits in cattle using the candidate pathway approach (Khatib et al., 2009a). Indeed, we showed that single genes from the POU1F1 pathway were associated with fertilization and early embry- onic survival rates, the 2 primary components of early pregnancy. Yet, these genes were identified in an IVF system that can only mimic the natural circumstance. Thus, in these IVF experiments we estimated direct effects of cows on fertility traits. In contrast, in the current study, we estimated bull effects on fertility. The question of whether embryonic survival (a fertility component) is a trait of the embryo or of the mother has long been debated in the literature (Morris and Diskin, 2008). In previous studies, we showed that genotypes of FGF2 and STAT5A were associated with female fertility traits (Khatib et al., 2008a,b). In this study, genotypes of STAT5A and FGF2 were also associated with the fertility component of males. Thus, we conclude that at least for these 2 genes, both the male and the female components are needed for fertility or embryonic survival.

In a previous IVF study, we found STAT5A to be significantly associated with fertilization rate and early embryonic survival (Khatib et al., 2008b). Association results were further confirmed in larger data sets of IVF embryos (Khatib et al., 2009b). Additionally, expression analysis revealed that STAT5A is primarily monoallelically expressed in early embryonic stages but biallelically expressed in later fetal stages, and that monoallelic maternal expression of STAT5A was significantly higher in blastocysts compared with degenerate embryos (Khatib et al., 2009b). Using the same IVF system, POU1F1 (Khatib et al., 2009a) and FGF2 (Khatib et al., 2008a) also showed significant associations with the IVF fertility traits. Previous studies have reported the expression of FGF2 in all stages of oocyte maturation (Yoshida et al., 1998), in unfertilized oocytes and in blastocysts (Wang et al., 2009) in cattle. Importantly, it was found that oocytes carrying the $\mathrm{T}$ allele of SNP23 in the $5^{\prime}$ untranslated region of FGF2 showed a reduced fertilization rate and that segregation distortion leads to rarity of the TT genotype in the population. Although the mechanisms by which FGF2 affects fertilization of oocytes are not well understood, the association of this gene with ERCR provides additional support for its role in male fertility.

The associations of STAT5A and FGF2 with ERCR in this study not only validate our previous in vitro results, but also demonstrate the usefulness of the combination of the IVF system and the candidate pathway approach in choosing candidate genes affecting fertility traits. Validation of in vitro results in vivo has proven challenging. Several research groups have reported alterations in gene expression as a result of ART procedures. For example, Kues et al. (2008) identified about 1,800 transcripts that showed different expression profiles between in vivo- and in vitro-derived oocytes, with the majority of these genes upregulated in the in vivo 
Table 2. Summary statistics and Hardy-Weinberg equilibrium (HWE) tests for investigated SNP

\begin{tabular}{|c|c|c|c|c|}
\hline $\mathrm{SNP}^{1}$ & Genotype & $\mathrm{n}$ & $\mathrm{MAF}^{2}$ & HWE ( $P$-value) \\
\hline \multirow[t]{3}{*}{ FGF2.SNP23 } & GG & 113 & \multirow[t]{3}{*}{0.19} & \multirow[t]{3}{*}{0.062} \\
\hline & GT & 63 & & \\
\hline & $\mathrm{TT}$ & 2 & & \\
\hline \multirow[t]{3}{*}{ FGF2.SNP11646 } & $\mathrm{AA}$ & 23 & \multirow[t]{3}{*}{0.36} & \multirow[t]{3}{*}{0.973} \\
\hline & $\mathrm{AG}$ & 84 & & \\
\hline & GG & 72 & & \\
\hline \multirow[t]{3}{*}{ POU1F1 } & AA & 5 & \multirow[t]{3}{*}{0.16} & \multirow[t]{3}{*}{0.969} \\
\hline & $\mathrm{AC}$ & 48 & & \\
\hline & $\mathrm{CC}$ & 131 & & \\
\hline \multirow[t]{3}{*}{$G H$} & AA & 93 & \multirow[t]{3}{*}{0.24} & \multirow[t]{3}{*}{0.018} \\
\hline & $\mathrm{AB}$ & 76 & & \\
\hline & BB & 4 & & \\
\hline \multirow[t]{3}{*}{$P R L$} & AA & 1 & \multirow[t]{3}{*}{0.12} & \multirow[t]{3}{*}{0.56} \\
\hline & $\mathrm{AG}$ & 37 & & \\
\hline & GG & 129 & & \\
\hline \multirow[t]{3}{*}{ GHR } & AA & 69 & \multirow[t]{3}{*}{0.36} & \multirow[t]{3}{*}{0.316} \\
\hline & $\mathrm{AT}$ & 90 & & \\
\hline & $\mathrm{TT}$ & 20 & & \\
\hline \multirow[t]{3}{*}{$P R L R$} & AA & 137 & \multirow[t]{3}{*}{0.14} & \multirow[t]{3}{*}{0.505} \\
\hline & $\mathrm{AG}$ & 40 & & \\
\hline & GG & 5 & & \\
\hline \multirow[t]{3}{*}{ STAT5A } & $\mathrm{CC}$ & 63 & \multirow[t]{3}{*}{0.40} & \multirow[t]{3}{*}{0.379} \\
\hline & GC & 95 & & \\
\hline & GG & 26 & & \\
\hline \multirow[t]{3}{*}{$O P N$} & $\mathrm{CC}$ & 65 & \multirow[t]{3}{*}{0.40} & \multirow[t]{3}{*}{0.955} \\
\hline & $\mathrm{TC}$ & 87 & & \\
\hline & $\mathrm{TT}$ & 30 & & \\
\hline \multirow[t]{3}{*}{$U T M P$} & GG & 76 & \multirow[t]{3}{*}{0.34} & \multirow[t]{3}{*}{0.616} \\
\hline & GA & 85 & & \\
\hline & AA & 19 & & \\
\hline
\end{tabular}

${ }^{1} F G F 2=$ fibroblast growth factor $2 ; P O U 1 F 1=$ pituitary-specific positive transcription factor $1 ; G H=$ growth hormone; $P R L=$ prolactin; $G H R=$ growth hormone receptor; $P R L R=$ prolactin receptor; $S T A T 5 A=$ signal transducer and activator of transcription $5 \mathrm{~A} ; O P N=$ osteopontin; $U T M P=$ uterine milk protein.

${ }^{2}$ Minor allele frequency.

oocytes. In a comparison between expression profiles of cattle embryos produced in vivo by AI and those produced in vitro, Smith et al. (2009) reported the differential expression of 44 genes that were unique to the AI embryos and of 60 genes that were unique to the IVF embryos. In previous studies, STAT5A, FGF2, and
POU1F1 were not among the genes that showed differential expression between ART- and in vivo-produced embryos (Kues et al., 2008; Smith et al., 2009).

One limitation of the data set presented in this study is the small number of bulls analyzed for fertility. Nonetheless, these represented most available bulls from the

Table 3. Estimated differences between the 3 genotypes for each SNP selected in the final model

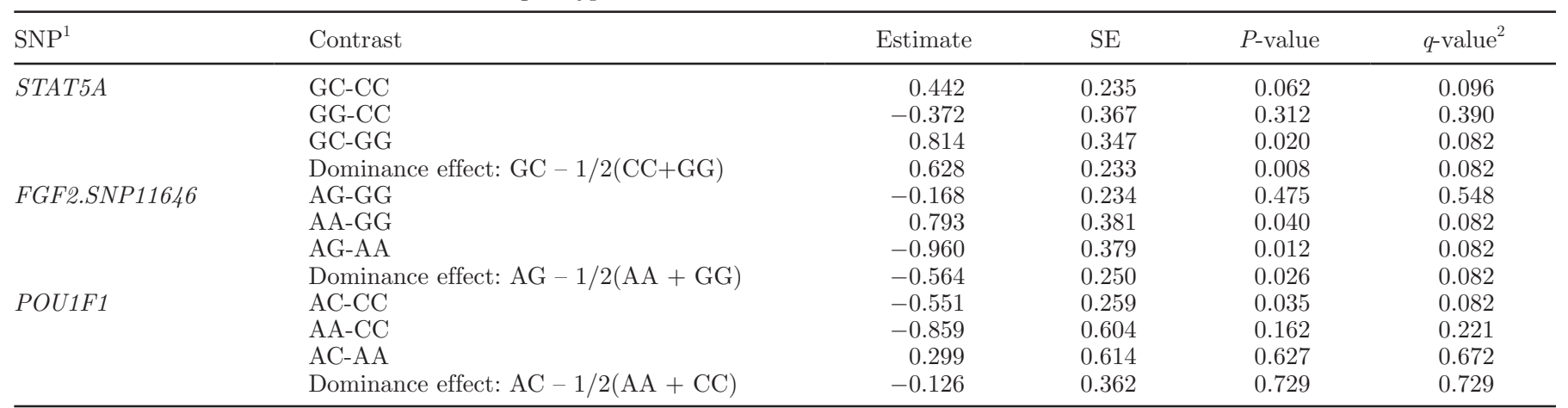

${ }^{1}$ STAT5A = signal transducer and activator of transcription $5 \mathrm{~A} ;$ FGF2 = fibroblast growth factor $2 ;$ POU1F1 = pituitary-specific positive transcription factor 1 .

${ }^{2} q$-value for false discovery rate calculation. See main text for explanation. 
period of the study from 4 of the 5 major AI studs in the United States. The small sample size limits the statistical power to detect associations. Consequently, it is more appropriate to interpret the $P$-values as the amount of evidence for association rather than for rejecting hypotheses below a threshold. A second limitation of the study is the different phenotypes used for validation of the in vitro results. Whereas our initial analysis of the IVF system included fertilization rate and early embryonic survival as measures of early pregnancy, the current analysis used ERCR data as an indicator of bull fertility. Yet, the phenotypic outcome of the data collected in both studies is a measure of fertility.

In recent years, several studies have reported the antagonistic relationship between high milk production of lactating dairy cows and fertility because of the intensive selection for milk yield traits (Dobson et al., 2008). In this study, we found that the AA genotype of FGF2 SNP11646 was associated with higher ERCR than were the AG and GG genotypes. In a previous study, we reported the association of the AA genotype with low milk production and productive life compared with the AG and GG genotypes (Wang et al., 2008). In this study, although not reaching a statistical significance, the AA genotype of POU1F1 showed a relatively lower ERCR compared with AG and GG genotypes. That same genotype has been found to be associated with high milk yield and productive life (Huang et al., 2008). Also, the G allele of STAT5A was associated with lower protein and fat percentages (Khatib et al., 2008b), which are negatively correlated with milk yield traits, and, in this study, with lower ERCR. These results confirm our previous findings that certain genotypes or alleles of some genes from the POU1F1 pathway are associated with high milk yield or composition and low fertility (Khatib et al., 2009a). These observations provide molecular evidence of the involvement of the same genes in both high milk production and low fertility trends observed in dairy cattle for the last 40 to $50 \mathrm{yr}$.

Given that genes in this study showing significant association with bull fertility were chosen using the candidate pathway approach, our results affirm the effectiveness of this approach in selecting candidate genes as previously demonstrated (Khatib et al., 2008a,b, 2009a).

\section{ACKNOWLEDGMENTS}

This study was supported by USDA Hatch grant WIS-142-PRJ17PH from the University of WisconsinMadison and by the Industrial and Economic Development Research grant No. 118-1180107 from Graduate School, University of Wisconsin-Madison. The authors thank Jenifer Cruickshank (SUNY Oswego, Oswego,
NY) for revising the manuscript. Special thanks are extended to Alta Genetics (Watertown, WI), ABS Global Inc. (Deforest, WI), Genex Cooperative/CRI (Shawano, WI), Accelerated Genetics (Baraboo, WI), and Select Sires Inc. (Plain City, OH) for donation of the semen to John Parrish for this fertility research.

\section{REFERENCES}

Beerda, B., J. Wyszynska-Koko, M. F. W. te Pas, A. A. C. de Wit, and R. F. Veerkamp. 2008. Expression profiles of genes regulating dairy cow fertility: Recent findings, ongoing activities and future possibilities. Animal 2:1158-1167.

Benjamini, Y., and Y. Hochberg. 1995. Controlling the false discovery rate: A practical and powerful approach to multiple testing. J. R. Stat. Soc., B 57:963-971.

Brym, P., S. Kamiński, and E. Wójcik. 2005. Nucleotide sequence polymorphism within exon 4 of the bovine prolactin gene and its associations with milk performance traits. J. Appl. Genet. $46: 179-185$

Clay, J. S., and B. T. McDaniel. 2001. Computing mating bull fertility from DHI nonreturn data. J. Dairy Sci. 84:1238-1245.

Dobson, H., S. L. Walker, M. J. Morris, J. E. Routly, and R. F. Smith. 2008. Why is it getting more difficult to successfully artificially inseminate dairy cows? Animal 2:1104-1111.

Huang, W., C. Maltecca, and H. Khatib. 2008. A proline-to-histidine mutation in POU1F1 is associated with production traits in dairy cattle. Anim. Genet. 39:554-557.

Khatib, H., W. Huang, X. Wang, A. H. Tran, A. B. Bindrim, V. Schutzkus, R. L. Monson, and B. S. Yandell. 2009a. Single gene and gene interaction effects on fertilization and embryonic survival rates in cattle. J. Dairy Sci. 92:2238-2247.

Khatib, H., C. Maltecca, R. L. Monson, V. Schutzkus, and J. J. Rutledge. 2009b. Monoallelic maternal expression of STAT5A affects embryonic survival in cattle. BMC Genet. 10:13.

Khatib, H., C. Maltecca, R. L. Monson, V. Schutzkus, X. Wang, and J. J. Rutledge. 2008a. The fibroblast growth factor 2 gene is associated with embryonic mortality in cattle. J. Anim. Sci. 86:2063-2067.

Khatib, H., R. L. Monson, V. Schutzkus, D. M. Kohl, G. J. M. Rosa, and J. J. Rutledge. 2008b. Mutations in the STAT5A gene are associated with embryonic survival and milk composition in cattle. J. Dairy Sci. 91:784-793.

Khatib, H., V. Schutzkus, Y. M. Chang, and G. J. M. Rosa. 2007. Pattern of expression of the uterine milk protein gene and its association with productive life in dairy cattle. J. Dairy Sci. 90:2427-2433.

Kues, W. A., S. Sudheer, D. Herrmann, J. W. Carnwath, V. Havlicek, U. Besenfelder, H. Lehrach, J. Adjaye, and H. Niemann. 2008. Genome-wide expression profiling reveals distinct clusters of transcriptional regulation during bovine preimplantation development in vivo. Proc. Natl. Acad. Sci. USA 105:1976819773.

Leonard, S., H. Khatib, V. Schutzkus, Y. M. Chang, and C. Maltecca. 2005. Effects of the osteopontin gene variants on milk production traits in dairy cattle. J. Dairy Sci. 88:4083-4086.

Miglior, F., B. L. Muir, and B. J. Van Doormaal. 2005. Selection indices in Holstein cattle of various countries. J. Dairy Sci. 88:1255-1263

Morris, D., and M. Diskin. 2008. Effect of progesterone on embryo survival. Animal 2:1112-1119.

Royal, M., G. E. Mann, and A. P. Flint. 2000. Strategies for reversing the trend towards subfertility in dairy cattle. Vet. J. 160:53-60.

Shook, G. E. 2006. Major advances in determining appropriate selection goals. J. Dairy Sci. 89:1349-1361.

Smith, S. L., R. E. Everts, L. Y. Sung, F. Du, R. L. Page, B. Henderson, S. L. Rodriguez-Zas, T. L. Nedambale, J. P. Renard, H. A. Lewin, X. Yang, and X. C. Tian. 2009. Gene expression profiling of single 
bovine embryos uncovers significant effects of in vitro maturation, fertilization and culture. Mol. Reprod. Dev. 76:38-47.

VanRaden, P. M., A. H. Sanders, M. E. Tooker, R. H. Miller, H. D. Norman, M. T. Kuhn, and G. R. Wiggans. 2004. Development of a national genetic evaluation for cow fertility. J. Dairy Sci. $87: 2285-2292$.

Veerkamp, R. F., and B. Beerda. 2007. Genetics and genomics to improve fertility in high producing dairy cows. Theriogenology 68S:S266-S273.

Viitala, S., J. Szyda, S. Blott, N. Schulman, M. Lidauer, A. MäkiTanila, M. Georges, and J. Vilkki. 2006. The role of the bovine growth hormone receptor and prolactin receptor genes in milk, fat and protein production in Finnish Ayrshire dairy cattle. Genetics $173: 2151-2164$.

Wang, X., C. Maltecca, R. Tal-Stein, E. Lipkin, and H. Khatib. 2008. Association of bovine fibroblast growth factor 2 (FGF2) gene with milk fat and productive life: An example of the ability of the candidate pathway strategy to identify quantitative trait genes. J. Dairy Sci. 91:2475-2480.

Wang, X., V. Schutzkus, W. Huang, G. J. Rosa, and H. Khatib. 2009. Analysis of segregation distortion and association of the bovine FGF2 with fertilization rate and early embryonic survival. Anim. Genet. 40:722-728.

Weigel, K. A. 2006. Prospects for improving reproductive performance through genetic selection. Anim. Reprod. Sci. 96:323-330.

Yoshida, Y., M. Miyamura, S. Hamano, and M. Yoshida. 1998. Expression of growth factor ligand and their receptor mRNAs in bovine ova during in vitro maturation and after fertilization in vitro. J. Vet. Med. Sci. 60:549-554.

Zhou, G. L., H. G. Liu, C. Liu, S. L. Guo, Q. Zhu, and Y. H. Wu. 2005. Association of genetic polymorphism in GH gene with milk production traits in Beijing Holstein cows. J. Biosci. 30:595598. 